\title{
THE ROLE OF GENDER IN LEARNERS' DIGITAL INTERACTION PREFERENCES
}

\author{
Muhittin Șahin ${ }^{1}$ and Dirk Ifenthaler ${ }^{2}$ \\ ${ }^{1}$ University of Mannheim, Germany; Ege University, Turkey \\ ${ }^{2}$ University of Mannheim, Germany; Curtin University, Australia
}

\begin{abstract}
A major criticism brought to digital learning environments was that the individual learning activities cannot be monitored consistently. However, recent advancements of educational data mining and learning analytics allow a precise tracking of learner activities. Previous studies focused on learners' navigation profiles, academic achievements, or motivation, while missing a closer look a gender differences. This study focusses on the interaction preferences of $N=161$ Bachelor students in a digital learning environment based on their gender. Within the scope of this research, interactions of the learners are defined as (a) learner-content, (b) learner-discussion (learner-learner), (c) learner-tutorial, (d) learner-video, and (e) learner-assessment. interaction preferences of the students were examined based on log data and evaluation data collected through digital instruments administered through a learning analytics system. For this purpose, adjusted residuals analysis has been conducted. Findings show that the interaction preferences of students differ throughout the study periods according to their gender. The findings obtained in this research can provide some initial suggestions for instructional designers of digital learning environments. Future research will include students' psycho-educational structures, such as learning strategies, motivational dispositions, and prior knowledge.
\end{abstract}

\section{KEYWORDS}

Interaction Preferences, Digital Learning Environment, Educational Data Mining, Learning Analytics, Gender Differences, Adjusted Residuals Analysis

\section{INTRODUCTION}

The advances of Information and Communication Technologies (ICT) provides multiple opportunities to support learners, teachers, and digital learning environments. One goal of using ICT in the field of education is to develop and improve learning processes without time and space constraints (Ji, Park, Jo, \& Lim, 2016). In this context, many digital learning environments have been developed and implemented in higher education institutions around the world. A major criticism brought to these digital learning environments was that the individual learning activities cannot be monitored consistently (Graf, Kinshuk, \& Liu, 2009). Since then, many approaches have been used to understand learners' learning profiles and to predict their future development based on such digital educational data and assessments (Ifenthaler, Pirnay-Dummer, \& Seel, 2010). However, recent advancements of educational data mining and learning analytics allow a precise tracking of learner activities, i.e., trace data in digital learning environments (Şahin, Keskin, Özgür, \& Yurdugül, 2017). Still, recording only trace data does not support a holistic perspective toward learning with regard to learners context and background (Ifenthaler \& Widanapathirana, 2014).

One strategy of educational data mining is the identification and classification of interaction profiles and patterns of learners in order to optimize digital learning environments within the context of learner needs and preferences. As such, it is possible to offer more appropriate and customizable learning environments to the learners. Successful applications have been studied with a focus on learners' navigation profiles (Blagojević \& Milosević, 2013; Graf, Kinshuk, \& Liu, 2009), academic achievements (Jo, Yu, Lee, \& Kim, 2015; Macfadyen \& Dawson, 2010), or motivation sources and cognitive strategies (Şahin et al., 2017; Keskin \& Yurdugül, 2019). 
Within the scope of this research, the interaction preferences of students in a digital learning environment were examined based on their gender. In addition, the interaction preferences of the students were examined according to different phases of learning during a 12-week semester at a higher education institution.

\section{BACKGROUND}

\subsection{Learning Management Systems and Learners' Preferences}

In recent years, it is possible to see that the education paradigm has shifted from one size fits all to an adaptive and customizable approach (Brusilovsky \& Henze, 2007). In this context, it is also seen that digital learning environments are used extensively by higher education institutions. Especially, Learning Management Systems (LMS) are used remarkably (Brown, Dehoney, \& Millichap, 2015). LMS is a software designed to help instructors in order to achieve their pedagogical goals by presenting learning content to the students and managing users and rights on the platform (Ifenthaler, 2012; Machado \& Tao, 2007). LMSs are used to manage the learning process and learning content (Ji et al., 2016; Ifenthaler \& Pirnay-Dummer, 2011) and include several opportunities for stakeholders such as presenting the learning content, conducting exams, collecting assignments, and documenting students' learning process. One of the key features of such digital learning environments are the collection of various interaction types. Interaction has become even more valuable, especially with the emergence of new distance education programs that promote interaction at various levels and types (Brown \& Long, 2006). It is possible to consider these types of interactions mainly as learner-content, learner-instructor and learner-learner interactions, which are put forth by Moore (1989). In addition, recent developments focus on the learner-assessment interaction type (Şahin et al., 2017). Within the scope of this research, the LMS interactions of the learners are defined as (a) learner-content, (b) learner-discussion (learner-learner), (c) learner-tutorial, (d) learner-video, and (e) learner-assessment.

Data of learners' interactions are stored unstructured in LMS environments (Šimić, Gašević, \& Devedžić, 2004). This log data may contain multiple ways for determining learning profiles and patterns of learners. The learners' learning profile must be determined in order to support the learning process and present appropriate artefacts and actions in a digital learning environment (Ifenthaler, 2015). Current studies focusing on learning profiles of learners in digital learning envirnments focus on log data (Keskin, Şahin, \& Yurdugül, 2019; Blagojević, M., \& Milosević, 2013; Macfadyen \& Dawson, 2010) or self-report data (Northrup, 2009; Rhode, 2009). In this research, interaction preferences of the students were examined based on log data and evaluation data collected through digital instruments administered through a learning analytics system. The interactions of students with the learning environment were considered as the number of clicks on the themes and the total frequencies were used in the standardized residual analysis. Detailed information about the analysis is presented in the method section.

\subsection{Research Questions}

This research focusses on interaction preferences of students in a digital learning environment with a specific focus on the influence of their gender. In addition, the learning experiences of the students were divided into three periods of study during the course of the semester. Accordingly, three research questions have been investigated:

1. Do the interaction preferences differ between females and males in the first study period?

2. Do the interaction preferences differ between females and males in the second study period?

3. Do the interaction preferences differ between females and males in the third study period? 


\section{METHOD}

\subsection{Context and Participants}

The study followed an evidence-centered design approach (Behrens, Mislevy, Dicerbo, \& Levy, 2012). Student and evaluation data were collected while implementing the learning analytics system LeAP (Learning Analytics Profile; Klasen \& Ifenthaler, 2019) into the productive university systems, such as the learning management system and the student management system. The descriptive information about the participants is presented in Table 1 .

Table 1. Descriptive information about the participants

\begin{tabular}{lll}
\hline Gender & Frequency & Ratio \\
\hline Female & 106 & $66 \%$ \\
Male & 55 & $34 \%$ \\
Total & 161 & $100 \%$ \\
\hline
\end{tabular}

As seen in Table 1, participants of the study were 161 students (106 female, 55 male) enrolled in a Bachelors program focusing on Economic and Business Education at an European university. The average age of the participants was 22.97 years $(\mathrm{SD}=2.92)$ and their average course load in the semester of data collection was six courses $(\mathrm{SD}=2.11)$. Participants received one credit hour for participating in the study.

The course of study focused on quantitative research methods and included weekly face-to-face lectures as well as online materials through a learning management system such as lecture slides and video recordings, self-assessments, reading assignments and discussion forums. In addition, students worked in small groups (max. 5) on a research project. The course concluded with a written exam at the end of the semester.

\subsection{Data Collection Tools}

Data used in this research consists of log data recorded through the universities LMS and learning analytics system LeAP. Data includes nine-week interactions of students with the digital learning environment. There are five different interaction themes: student-content, student-discussion, student-tutorial, student-video, and student-assessment. First, data pre-processing was applied. All data were cleaned while pre-processing and data quality checks were conducted. Then, the data were converted into contingency tables.

\subsection{Data Analysis}

Chi-square analysis is used when both the dependent and independent variables are discrete. However, in chi-square analysis, the number of categories in the variables is limited with two. Adjusted residuals analysis is used when the dependent and independent variables have more than two categories (Cornell Statistical Consulting Unit, 2018). Within the scope of this research, since there are contingency tables of $5 * 2$, the standardized residual analysis was used as the Chi-square post-hoc test. The standardized residual value should be a $<.05+-1.96$ (Field, 2018). Bonferroni adjustment is made in order to test the significance level in these contingency tables. Bonferroni adjustment is carried out to maintain a sufficient error rate for contingency table dimensions (MacDonald \& Gardner, 2000).

\section{RESULTS}

The semester included twelve weeks of study, however, students lived experience in the digital learning environment was limited to nine weeks as through administrative constraints of the university. The learning experiences of students were examined as three different study periods. Each period is considered as three weeks (first period 1-3; second period 4-6; third period 7-9). The findings are presented based on these periods following the above mentioned research questions. 


\subsection{First Period Interaction Preferences of Students}

The first period includes the first three weeks (1-3 weeks) of students' digital learning environment interactions. The observed and expected interaction frequencies of the students in this period are presented in Table 2.

Table 2. Students' observed and expected interaction preferences in the first period

\begin{tabular}{lllllll}
\hline & Gender & Content & Discussion & Tutorial & Video & Assessment \\
\hline Observed & Male & 6558 & 1168 & 23 & 464 & 659 \\
& Female & 16782 & 1142 & 7859 & 5291 & 710 \\
Expected & Male & 5093.28 & 504.09 & 1720.02 & 1255.86 & 298.74 \\
& Female & 18246.72 & 1805.91 & 4499.14 & 4499.14 & 1070.26 \\
\hline
\end{tabular}

As shown in Table 2, students interact intensely with the content. On a descriptive level, female students show higher interact male students. In order to test for significant differences, adjusted residuals analysis has been conducted. The findings obtained from this analysis are presented in Table 3.

Table 3. Results of adjusted residuals analysis about interaction preferences for the first period

\begin{tabular}{llllll}
\hline Gender & Content & Discussion & Tutorial & Video & Assessment \\
\hline Male & $\mathbf{2 0 . 5 2}$ & $\mathbf{2 9 . 5 7}$ & $\mathbf{- 4 0 . 9 2}$ & $\mathbf{- 2 2 . 3 4}$ & $\mathbf{2 0 . 8 4}$ \\
Female & $\mathbf{- 1 0 . 8 4}$ & $\mathbf{- 1 5 . 6 2}$ & $\mathbf{2 1 . 6 2}$ & $\mathbf{1 1 . 8 1}$ & $\mathbf{- 1 1 . 0 1}$ \\
\hline
\end{tabular}

Adjusted $p<.005 ; \mathrm{z}$ threshold $>2.81$

As seen in Table 3. the interaction preferences of students significantly differ based on their gender. The values which are seen in Table 3 are $\mathrm{z}$ scores. After Bonferroni adjusted in the analysis phase, the $\mathrm{z}$ threshold value was obtained as 2.81. Accordingly, it was determined that male students preferred to interact with content, discussion, and assessment in the first period. It can be said that female students prefer to interact with tutorials and videos compared to female students.

\subsection{Second Period Interaction Preferences of Students}

The second period includes weeks 4-6 of the semester. The observed and expected interaction frequencies of the students' interactions in this period are presented in Table 4.

Table 4. Students' observed and expected interaction preferences in the second period

\begin{tabular}{lllllll}
\hline & Gender & Content & Discussion & Tutorial & Video & Assessment \\
\hline Observed & Male & 52025 & 976 & 47940 & 3488 & 1435 \\
& Female & 66439 & 5472 & 59485 & 59292 & 19549 \\
Expected & Male & 39674.26 & 2159.47 & 35977.24 & 21025.37 & 7027.66 \\
& Female & 78789.74 & 4288.53 & 71447.76 & 41754.63 & 13956.34 \\
\hline
\end{tabular}

As shown in Table 4, students interact intensely with the content. On descriptive level, female students interact with tutorials and videos. Likewise, male students interact with not only content but also the tutorial. In addition, female students interact more frequently than male students. In order to test for significant differences, adjusted residuals analysis has been conducted. The findings obtained from this analysis are presented in Table 5.

Table 5. Results of adjusted residuals analysis about interaction preferences for the second period

\begin{tabular}{llllll}
\hline Gender & Content & Discussion & Tutorial & Video & Assessment \\
\hline Male & $\mathbf{6 2 . 0 1}$ & $\mathbf{- 2 5 . 4 7}$ & $\mathbf{6 3 . 0 7}$ & $\mathbf{- 1 2 0 . 9 5}$ & $\mathbf{- 6 6 . 7 1}$ \\
Female & $\mathbf{- 4 4 . 0 0}$ & $\mathbf{1 8 . 0 7}$ & $\mathbf{- 4 4 . 7 5}$ & $\mathbf{8 5 . 8 2}$ & $\mathbf{4 7 . 3 4}$ \\
\hline
\end{tabular}

Adjusted $p<.005 ; \mathrm{z}$ threshold $>2.81$

As shown in Table 5, the interaction preferences of students significantly differ between female and male students. Accordingly, male students preferred to interact with content and tutorial in the second period. Further, female students prefer to interact with discussion, video, and assessments. 


\subsection{Third Period Interaction Preferences of Students}

The third period includes the last three weeks (7-9 weeks) of students' digital learning environment interactions. The observed and expected interaction frequencies of the students in this period are presented in Table 6.

Table 6. Students' observed and expected interaction preferences in the third period

\begin{tabular}{lllllll}
\hline & Gender & Content & Discussion & Tutorial & Video & Assessment \\
\hline Observed & Male & 33311 & 291 & 18106 & 6783 & 2014 \\
& Female & 80178 & 5838 & 37020 & 54967 & 2574 \\
Expected & Male & 28482.64 & 1538.21 & 13835.12 & 15497.56 & 1151.46 \\
& Female & 85006.36 & 4590.79 & 41290.88 & 46252.44 & 3436.54 \\
\hline
\end{tabular}

As shown in Table 6, students interact intensely with the content. On a descriptive level, female students interact with tutorials and videos. In addition, female students interact more frequently than male students. Adjusted residuals analysis was applied to test for significant differences. The findings obtained from this analysis are presented in Table 7.

Table 7. Results of adjusted residuals analysis about interaction preferences for the third period

\begin{tabular}{llllll}
\hline Gender & Content & Discussion & Tutorial & Video & Assessment \\
\hline Male & $\mathbf{2 8 . 6 1}$ & $\mathbf{- 3 1 . 8 0}$ & $\mathbf{3 6 . 3 1}$ & $\mathbf{- 7 0 . 0 0}$ & $\mathbf{2 5 . 4 2}$ \\
Female & $\mathbf{- 1 6 . 5 6}$ & $\mathbf{1 8 . 4 1}$ & $\mathbf{- 2 1 . 0 2}$ & $\mathbf{4 0 . 5 2}$ & $\mathbf{- 1 4 . 7 1}$ \\
\hline
\end{tabular}

Adjusted $p<.005 ; \mathrm{z}$ threshold $>2.81$

As shown in Table 7, the interaction preferences of students significantly differ based on their gender. Accordingly, male students preferred to interact with content, tutorial and assessment in the third period and female students prefer to interact with discussion and video. After the students' interaction preferences for three different periods are given based on gender, the interaction preferences for each gender are presented in Table 8.

Table 8. Student interaction preferences based on their gender

\begin{tabular}{llll}
\hline Gender & First period & Second period & Third period \\
\hline Male & Content & Content & Content \\
& Discussion & Tutorial & Tutorial \\
& Assessment & & Assessment \\
Female & Tutorial & Discussion & Discussion \\
& Video & Video & Video \\
& & Assessment & \\
\hline
\end{tabular}

As shown in Table 8, the interaction preferences of students differ throughout the study periods according to their gender. For example, male students preferred to interact with content, discussion and assessment in the first period. However, in the second period, male students chose to interact with content and tutorial. According to these findings, it is possible to say that students have different interaction preferences in different periods. Another point that draws attention to the findings is that female students consistently prefer to interact with video and male students to interact with content.

\section{DISCUSSION}

In this study, interaction preferences of students in a digital learning environment were examined based on their gender. According to the findings, it was concluded that students' online interaction preferences are different based on both their gender and study period. The interaction preferences of male students are as follows: a) for the first period; content, assessment, and discussion b) for the second period; content ant tutorial and c) for the third period; content, tutorial, and assessment. The interaction preferences of female students are as follows: a) for the first period; tutorial and video b) for the second period; discussion, video, and assessment and c) for the third period; discussion and video. 
Another finding obtained within the scope of the research points toward a the preference of male students being the interaction with the textual content and female students prefer to interact with the video content. This finding is consistent with Ching and Hsu (2015) who found that female students prefer to interact with audio/video discussions and male students prefer text-based discussions. Female students seem to prefer to interact with video content because of including more personal and emotional forms of language (Ching $\&$ Hsu, 2015). However, more studies are needed to foster these findings on large-scale.

Findings obtained in this research can provide some initial suggestions for instructional designers of digital learning environments (Ifenthaler, 2017). However, in this study, interaction preferences of students are limited by gender. In further research, it is planned that students' psycho-educational structures will be examined, such as learning strategies, motivational dispositions, and prior knowledge. In this way, it is thought that further recommendations can be obtained for researchers and learning designers in order to design appropriate digital learning environments.

\section{CONCLUSION}

Epistemological changes in the 1990s led to the emergence of student-centered innovative approaches of learning environments (Land \& Hannafin, 2009). With learner-centered learning approach learning environments that are designed based on the interests and needs of individuals are provided and thus more complex tasks can be done and understanding can be deepened (Land \& Hannafin, 1997). Within the scope of this research, the interaction preferences of the students who are one of the most important stakeholders of student-centered approaches were determined. Learning environments can be designed in accordance with the needs and individual characteristics by determining the preferences of the students (Ifenthaler, 2015). According to the findings, it was found that the interaction preferences of students become different based on their gender. Besides, adjusted residuals analysis was performed in order to determine the interaction preferences. It is thought that the use of adjusted residuals analysis in discovering learning patterns from interaction data will be an example for researchers.

\section{REFERENCES}

Behrens, J., Mislevy, R., Dicerbo, K., \& Levy, R. (2012). Evidence centered design for learning and assessment in the digital world. In M. Mayrath, J. Clarke-Midura, D. Robinson, \& G. Schraw (Eds.), Technology-based assessments for 21 st century skills (pp. 13-54). Charlotte, NC: Information Age Publishers.

Blagojević, M., \& Milosević, M. (2013). Collaboration and learning styles in pure online courses: an action research. Journal of Universal Computer Science, 19(7), 984-1002.

Brown, M., \& Long, P. (2006). Trends in learning space design. Learning Spaces,9, 1-9.

Brown, M., Dehoney, J., \& Millichap, N. (2015). The next generation digital learning environment. A Report on Research. ELI Paper. Louisville, CO: Educause April.

Brusilovsky, P., \& Henze, N. (2007). Open corpus adaptive educational hypermedia. In P. Brusilovsky, A. Kobsa, $\&$ W. Nejdl (Eds.), The adaptive web: Methods and strategies of web personalization (pp. 671-696). Berlin: Springer. LNCS 4321.

Ching, Y. H., \& Hsu, Y. C. (2015). Online graduate students' preferences of discussion modality: Does gender matter? Journal of Online Learning and Teaching, 11(1), 31-41.

Cornell Statistical Consulting Unit. (2018). Adjusted standardized residuals for interpreting contingency tables (Report No. 95). Retrieved from https://www.cscu.cornell.edu/news/statnews/stnews95.pdf

Field, A. (2018). Discovering Statistics Using IBM SPSS Statistics.

Graf, S., Kinshuk, \& Liu, T. C. (2009). Supporting teachers in identifying students' learning styles in learning management systems: An automatic student modelling approach. Journal of Educational Technology \& Society, 12(4), 3-14.

Ifenthaler, D. (2012). Learning management systems. In N. M. Seel (Ed.), Encyclopedia of the sciences of learning (Vol. 12, pp. 1925-1927). New York, NY: Springer.

Ifenthaler, D. (2015). Learning analytics. In J. M. Spector (Ed.), The SAGE encyclopedia of educational technology (Vol. 2, pp. 447-451). Thousand Oaks, CA: Sage. 
Ifenthaler, D. (2017). Learning analytics design. In L. Lin \& J. M. Spector (Eds.), The sciences of learning and instructional design. Constructive articulation between communities (pp. 202-211). New York, NY: Routledge.

Ifenthaler, D., \& Pirnay-Dummer, P. (2011). States and processes of learning communities. Engaging students in meaningful reflection and learning. In Social media tools and platforms in learning environments (pp. 81-94). Springer, Berlin, Heidelberg.

Ifenthaler, D., \& Widanapathirana, C. (2014). Development and validation of a learning analytics framework: Two case studies using support vector machines. Technology, Knowledge and Learning, 19(1-2), 221-240.

Ifenthaler, D., Pirnay-Dummer, P., \& Seel, N. M. (Eds.). (2010). Computer-based diagnostics and systematic analysis of knowledge. New York: Springer.

Ji, H., Park, K., Jo, J., \& Lim, H. (2016). Mining students activities from a computer supported collaborative learning system based on peer to peer network. Peer-to-Peer Networking and Applications, 9(3), 465-476.

Jo, I. H., Yu, T., Lee, H., \& Kim, Y. (2015). Relations between student online learning behaviour and academic achievement in higher education: A learning analytic approach. In G. Chen, V. Kumar, Kinshuk, R. Huang, \& S. C. Kong (Eds.), Emerging Issues in Smart Learning (pp. 275-286). Berlin: Springer.

Keskin, S., \& Yurdugül, H. (2019). Factors Affecting Students' Preferences for Online and Blended Learning: Motivational vs. Cognitive. European Journal of Open, Distance and E-learning, 22(2), 72-86.

Keskin, S., Şahin, M., \& Yurdugül, H. (2019). Online Learners' Navigational Patterns Based on Data Mining in Terms of Learning Achievement. In Learning Technologies for Transforming Large-Scale Teaching, Learning, and Assessment (pp. 105-121). Springer, Cham.

Klasen, D., \& Ifenthaler, D. (2019). Implementing learning analytics into existing higher education legacy systems. In D. Ifenthaler, J. Y.-K. Yau, \& D.-K. Mah (Eds.), Utilizing learning analytics to support study success (pp. 61-72). New York, NY: Springer.

Land, S. \& Jonassen, D.H. (2009). Student-centered learning environments. (Eds: Jonassen, D.H \& Land, S.). In Theoretical foundations of learning environments. Routledge.

Land, S. M., \& Hannafin, M. J. (1997). Patterns of understanding with open-ended learning environments: A qualitative study. Educational Technology Research and Development, 45(2), 47-73.

MacDonald, P. L., \& Gardner, R. C. (2000). Type I error rate comparisons of post hoc procedures for I j Chi-Square tables. Educational and Psychological Measurement,60(5), 735-754.

Macfadyen, L. P., \& Dawson, S. (2010). Mining LMS data to develop an -early warning system for educators: A proof of concept. Computers \& Education, 54, 588-599.

Machado, M., \& Tao, E. (2007). Blackboard vs. Moodle: Comparing user experience of learning management systems. In 2007 37th annual frontiers in education conference-global engineering: Knowledge without borders, opportunities without passports (pp. S4J-7). IEEE.

Moore, M. G. (1989). Three types of interaction. The American Journal of Distance Education, 3(2), 1-7.

Northrup, P. T. (2009). Online learners' preferences for interaction. The perfect online course: Best practices for designing and teaching, 463-473.

Rhode, J. (2009). Interaction equivalency in self-paced online learning environments: An exploration of learner preferences. The International Review of Research in Open and Distributed Learning, 10(1), 1-23.

Şahin, M., Keskin, S., Özgür, A., \& Yurdugül, H. (2017). Determination of interaction profiles based on learner characteristics in e-learning environment. Educational Technology Theory and Practice, 7(2), 172-192.

Šimić, G., Gašević, D., \& Devedžić, V. (2004). Semantic web and intelligent learning management systems. In Workshop on Applications of Semantic Web Technologies for e-Learning. 